* Cómo citar este artículo: Becerra Lagos, J. I. y Becerra Mayorga, W. (2021). Llorona de agua y duende de aire: el cronotopo en la narrativa plural de dos leyendas colombianas. Estudios de Literatura Colombiana 49, pp. 137-153. DOI: https://doi.org/10.17533/udea.elc.n49a08

1 https://orcid.org/0000-0003-3675-0105 chencho.becerra@gmail.com

Universidad Pedagógica y Tecnológica de Colombia, Colombia

2 https://orcid.org/0000-0002-7304-5125 wbecerra@uwo.ca

Universidad Pedagógica y Tecnológica de Colombia, Colombia

Editores: Andrés Vergara Aguirre, Christian Benavides Martínez

Recibido: 13.02 .2021

Aprobado: 21.05.2021

Publicado: 30.06 .2021

Copyright: (92021 Estudios de Literatura Colombiana. Este es un artículo de acceso abierto distribuido bajo los términos de la Licencia Creative Commons AtribuciónNo comercial - Compartir igual 4.0 Internacional

\section{LLORONA DE AGUA Y DUENDE DE AIRE: EL CRONOTOPO EN LA NARRATIVA PLURAL DE DOS LEYENDAS COLOMBIANAS*}

\author{
Llorona of Water and Leprechaun of \\ Air: the Chronotope in the Plural \\ Narrative of two Colombian Legends
}

José Inocencio Becerra Lagos, ${ }^{1}$ Witton Becerra Mayorga ${ }^{2}$

\begin{abstract}
Resumen: Este trabajo crítico analizará dos leyendas recogidas en el municipio de Susacón, Boyacá, a la luz del concepto de cronotopo desarrollado por Mijail Bajtín, con el fin de develar algunos elementos simbólicos de la construcción cultural de lo humano en la literatura campesina, de arraigo colectivo y oral. En principio se observará la historia de La Llorona en diferentes circunstancias en que es activa la presencia del agua. Luego serán revisadas las relaciones entre el duende y el aire teniendo como eje central un relato popular recogido a varias voces en que dicho personaje rapta a un niño.
\end{abstract}

Palabras clave: literatura tradicional colombiana; cronotopo; leyenda; agua; aire.

Abstract: This article will analyze two legends collected in Susacón, Boyacá, in light of the concept of chronotope developed by Mikhail Bakhtin, in order to unveil some symbolic elements pertaining to the cultural construction of the human in the traditional literature of collective and oral roots. First, the story of La Llorona will be observed under different circumstances in which the presence of water is active. Then, the relationship between Leprechaun and air will be reviewed, having as central axis a popular story collected in several voices in which this character kidnaps a child.

Key words: Traditional Colombian literature; chronotope; legend, water; air. 


\section{Introducción}

La principal idea expuesta por Bajtín en relación con el concepto de cronotopo es heredada de la teoría de la relatividad de Einstein, la cual declara la inseparabilidad del espacio-tiempo y puede ser resumida a través de la visión del tiempo como cuarta dimensión del espacio. Según esta condición, el tiempo puede ser visto en la totalidad espacial del mundo, y el espacio es entendido y medido a través del tiempo, cuyo movimiento intensifica la vida de los lugares. Observar un árbol mientras cambia de forma y color sería un buen ejemplo de cómo puede ser visto el tiempo a través del espacio y viceversa. Otra forma de percibirlo sería teniendo conciencia de que el tiempo no es una categoría abstracta (como consideraba Kant), sino un elemento central de la constitución concreta de la realidad, y que el espacio no es un fondo inmóvil, estático, que no acontece, sino que se transforma todo el tiempo. Lo que propone Bajtín es una lectura del cronotopo real en el sistema artístico de la novela: observar sus motivos como una refracción de la conciencia cultural de una época. "Por eso interpreta esos motivos como traducción semiótica de un tiempo y espacio reales e, ideológicamente, de una concepción del hombre y de una organización social simbólica" (Arán, 2009, p. 128). Las convergencias de espacio-tiempo estarían tejidas en el microuniverso del texto y revelarían la construcción de la imagen de lo humano en un marco cultural específico.

Bajtín estudia este fenómeno en el género novelesco, desde la novela griega antigua hasta Rabeláis. En este trabajo hemos realizado un desplazamiento teórico hacia el género de la leyenda (campesina y de registro oral) para observar cómo inciden las relaciones cronotópicas en la imagen del ser humano que construyen las literaturas campesinas. Entre los géneros de la literatura oral elegimos la leyenda como objeto de estudio, por ser la que ubica con mayor precisión los hechos narrados en un lugar y momento específicos de la historia a través de la memoria colectiva. Los relatos estudiados hacen parte del material recogido en una etapa de trabajo de campo del proyecto Mediación de lecturas y escrituras en contextos rurales, ${ }^{1}$ realizada en el municipio de Susacón.

$\mathrm{Al}$ tratarse de narrativas de arraigo campesino, el lugar de la naturaleza es preponderante en las historias sobre La Llorona y el duende, a través de la representa-

1 Realizado a través de una alianza entre la Agencia Cultural de Tunja del Banco de la República, la Fundación Universitaria Juan de Castellanos y la Arquidiócesis de Tunja. 
ción simbólica de dos de sus elementos, agua y aire, que aparecen constantemente como sujetos vivos, especialmente en el nudo trágico de las leyendas. Es por ello que en algunas partes del texto complementaremos la argumentación con ideas que han sido construidas desde la ecocrítica, los imaginarios de agua y la imaginación de la materia, ideas que observan el lugar de la naturaleza en la literatura desde un ángulo parecido. Sin embargo, mantendremos al cronotopo como tema central, debido a que los registros de las relaciones espaciotemporales en las apariciones de La Llorona y el duende, del agua y del aire, son los que irán develando la imagen que la comunidad campesina ha construido alrededor de las figuras de la mujer, el niño, el castigo, la muerte, el aborto y el rapto, componentes centrales (en los dos relatos) de una imagen mayor sobre la concepción cultural local que se ha gestado del ser humano.

\section{Llorona de agua}

Para Ong (1996), el pensamiento y la expresión orales están más conectados con el mundo humano vital que la escritura (pp. 48-55). De ahí que la leyenda vive en lo concreto, recorre las zonas de los pueblos conocidas por la gente e incluso deja su voz, hechos y personajes en lugares especiales. Martos-Núñez y Martos-García (2015) analizan constantemente dichos lugares desde un enfoque que está basado en el concepto de "imaginarios de agua". Tales imaginarios develan valores culturales que el agua tiene en lugares mito-poéticos, lugares de memoria (sagrados o profanos) en los que ocurre la leyenda (pp. 126-130). Díaz González (2007) sintetiza este punto de la siguiente forma: "es como si las historias se contaran a sí mismas a través de lo humano, como si fueran relatos a propósito de ciertos lugares que ya existian antes de que vinieran a narrarlos quienes los contaron y los cuentan” (p. 161. Énfasis añadido). Es así como también en la teoría se dejan ver juntos el espacio y el tiempo.

El reiterado recurso de la delimitación cronotópica es un valor central del relato oral tanto en narraciones colectivas como en aquellas en las que el interlocutor lía la trama al propio tiempo y espacio de su vida. ${ }^{2}$ De acuerdo con Bajtín (1989), "el pensamiento abstracto puede concebir por separado el tiempo y el espacio, pero la literatura considera el cronotopo en su total unidad y plenitud" (p. 393). Esa casual

2 No sería errada la generalización hacia la lírica campesina, sobre todo en el gusto que demuestra por enunciar el espacio: “allá arriba en aquel alto", “en el otro lao del río”, “en la puerta de mi casa”, "allá en el campo”, "en el Puente Real de Vélez”, etc. 
necesidad de juntura, de tejido de un “cuandónde” simultáneo, pertenece por igual a las oralituras indígenas contemporáneas, a los cuentos populares de tío conejo y tío tigre de origen africano — que aún se cuentan en las regiones costeras de Colombia-, al romancero y al Quijote. "El cronotopo, como categoría de la forma y del contenido, determina también (en una medida considerable) la imagen del hombre en la literatura, esa imagen es esencialmente cronotópica” (p. 238). Es por ello que, contrario a lo que sugiere Álvarez (2012, p. 80), consideramos que la integración de información de conocimiento cultural o de ubicación geográfica de los sitios donde ocurren los hechos de la leyenda no provoca una fuerte ruptura de la trama, sino que aporta significativamente a la secuencia temática y narrativa que sigue su relato.

Es en el sentir-sapiencial de la experiencia de lo legendario donde puede encontrarse un núcleo compartido por todas las tradiciones orales-colectivas y las vivencias personales: todos sienten algo que les permite preservar hacia adelante un saber. Por eso la leyenda es más dinámica y menos sagrada que el mito. Siguiendo la clasificación utilizada por Antonio Castaño (2014, pp. 39-40), los personajes aquí estudiados entran en la categoría de leyendas maravillosas, en el subgrupo de seres sobrenaturales y extraordinarios. Se trata de un motivo-personaje en el que caben "seres sobrenaturales, animales, entidades mágicas, curanderas y señoras del monte" (Álvarez, 2012, p. 43).

La comparación deja ver que La Llorona se esconde menos que el duende tanto como vemos y oímos con más frecuencia al agua que al aire. De igual manera, el aire es una experiencia que vivimos todo el tiempo, mientras que la relación con el agua es más exclusiva: solo unos afortunados pueden escucharla con frecuencia. Por eso en esta leyenda no hay un relato-base desde el cual invocar otras versiones. En los más de diez relatos recogidos, encontramos cuatro opciones de contacto del mismo narrador o de otra persona con La Llorona: escuchándola, viéndola, cruzándosela por un camino o siendo directamente abordados por ella. Estos relatos (que suceden en cinco veredas distintas) también dan cuenta de tres apariciones posibles en cuanto a personajes: los narradores se encuentran con La Llorona, con ella y su hijo o a ambos con el diablo.

Observemos uno de los relatos más atemorizantes, de voz de Rafael Blanco, en el que aparecen los tres personajes. Iremos detallando los rasgos de espacio y tiempo que van denotando movimiento: 
Veníamos mi papá y yo con unos cabros del páramo (cuando eso no había transporte y había que coger con los animales de cabestro, y a veces le agarraba a uno la noche) y veníamos por ahí a las nueve, ocho y media, en una quebrada que llaman la 2uebrada de La Artesa, con unos cinco cabros amarrados. Él venía adelante y traía al caballo en el que montaba y yo traía a los chivos de cabresteo. Al llegar a la quebrada había un altibajo feo, él se alcanzó a adelantar y subió como unos veinte o treinta metros de la quebrada para acá cuando yo vide la llorona que bajaba quebrada abajo, ahí sí vide yo un niño chiquito, viejito, viejito pero chiquito, arrugado y barbudo, y la berrietas a la pata que ya casi le ponía las manos para alcanzarlo. Y el diablo echándole juete. A los tres los vi.

Y llegamos y yo a lo que la vide que venía, eso fue en cuestión de segundos que la vide como a una distancia de aquí a la puerta y yo pegué el berrido también y los cabros pegaron el brinco contra la quebrada y salieron adelante y me raparon el lazo y pasaron al lado de la bestia que llevaba mi papá, y él se devolvió ligerito y fue y me agarró de los brazos y me dijo qué fue, qué fue, y le dije: mire que vi un espanto, la llorona. No, no, no, eso no es llorona, son unos jaras que tan peleando. Pero no, yo estaba viendo a la llorona, al bebé viejo y al diablo igual a un hombre que echaba candela. Bueno, cuando llegamos a la casa él no me dejó entrar a que prendieran luz, porque se priva uno ahí mismo si ve la luz, es lo que dicen, no tengo conocimiento, y me entraron a la pieza y me acostaron sin prender luz (Blanco, 2019, s. p.).

El narrador se refiere al páramo de Güina — como veremos para el caso del duende, el páramo es el escenario de la aparición del personaje fantástico-, uno de los dos que rodean al municipio. La atmósfera creada por la narración es la de un lugar solitario, helado y terrorífico. A pesar de lo escabrosos y disímiles, los caminos recorridos por el observador y La Llorona parecen paralelos: uno de tierra y otro de agua, en los que cada uno va empujado por su grito (“yo pegué el berrido también”), provocado respectivamente por un miedo profundo y un castigo violento. Si bien no hay un cruce, la conciencia de lo visto por el narrador y su percepción del espacio nos insertan en el cronotopo del camino que Bajtín (1989) resalta como central, “debido a todos los tipos de encuentro que permite” (pp. 250-251). Efectivamente, las demás narraciones también resaltan la materialidad del camino como punto de avance, encuentro, separación, cruce y viaje:

Yo en lugar de tarme quieto salía a correr por un camino abajo. Alcancé a cruzar la quebrada del Alto de La Llorona, y la crucé antes de que ella bajara en el camino, y le sentía así como las garras y el chino corría y la llamarada de candela se había puesto adelante (Mesa, 2019, s. p.).

En la unidad que imanta a todos los relatos nos encontramos con una mujer que ha abortado a su(s) hijo(s) en un hilo de agua (quebrada o pozo) y que recibe un castigo que se prolonga hasta después de la muerte. El aborto no se detalla, solo se inscribe en un afluente de agua. El castigo, en cambio, es descrito en la mayoría de las versiones como un jay! lastimero, aunado cíclicamente a los golpes dados por el fuete del diablo. Además, quien ve y escucha a La Llorona ejerce —usando lo que la leyenda le ha dicho desde otras voces-veces- un rol de juez de la mujer, que influye directamente en 
su encuentro con ella: la maldice porque sabe que así puede distanciarla. Podríamos hablar entonces del cronotopo del crimen y el castigo en el que un hecho ejecutado en un instante y catalogado como terrible despierta una consecuencia larga y penosa para quien lo ha cometido. ${ }^{3}$

Separemos este cronotopo de crimen y castigo en sus dos etapas a través de fragmentos de algunas de las explicaciones populares: de acuerdo con Saúl Lagos (2019), “es la mujer que resulta embarazada y está pa' dar un niño, entonces ella por no criar esa criatura, toman cualquier vaina pa' abortar. $\mathrm{Y}$ esas viejas se van a una quebrada, a un pozo para echar la criatura ahî" (s. p. Énfasis añadido); según Julia Sandoval (2019), "en ese momento reconocí que era lo que ya me habían contado mis antepasados de la mujer que mataba a un niño, al hijo” (s. p. Énfasis añadido); por su parte, Álvaro Mesa (2019) menciona que "esos son hechos que cometen mujeres: matan los hijos, los echan al agua y cuando mueren comienzan a purgar sus penas por el tiempo en que cometieron el hecho" (s. p. Énfasis añadido). Subrayamos el paso de lo singular a lo plural, el valor de autoridad moral colectiva del saber de y el juzgar a La Llorona, y la marcación del carácter femenino del crimen. Este es, pues, el tiempo del miedo en que la mujer no desea ser madre y decide interrumpir su embarazo. Lo que une a casi todas las versiones es el escenario líquido de la muerte del niño. Efectivamente, el agua es un símbolo que liga oposiciones: lo funerario con la fertilidad y la fecundidad (Martos-Núñez y Martos-García, 2015, p. 124); es al tiempo las mismas y otras aguas, y recuerda de forma simultánea múltiples mitos esenciales presentes prácticamente en todas las culturas: la laguna en la que nacen todas las formas de vida; las aguas informes y solitarias del origen del mundo, con cuya separación Dios no se alegra en el Génesis (Illich, 2008, p. 435); la purificación líquida del cuerpo y del espíritu, y el diluvio. Pensemos entonces este tipo de aborto hídrico desde la misma materialidad de las aguas. Nos encontramos ante un elemento que excede su presencia e influencia sobre otros cuerpos; "muy poco o mucho de un elemento puede provocar muertes comunes: deshidratación, deflagración, hipotermia" (Cohen y Duckert, 2015, p. 13). Por otro lado, las cosas ocurren antes de tiempo: de la estática agua vital de la placenta, el niño sale al agua helada y dinámica ción-beatitud (p. 271). En el caso de La Llorona la línea se corta en la mitad, la curva nunca asciende y la condena solo cesará con la muerte. 
que corre (llevándolo a morir), de forma tan precoz como el preadolescente que el duende se lleva, según veremos más adelante. El pueblo no perdona que una madre ocasione este tránsito, y el río no lo olvida. ${ }^{4}$

En segundo lugar está el castigo como cronotopo cíclico. Al igual que en un rito, la mujer repite el acto en el mismo momento del año en que lo hizo: "Esa vaina no pasa hasta que la mujer se muera, desde el tiempo que esté viviendo, por el tiempo que hizo cada año pasa esa vaina” (Lagos, 2019, s. p. Énfasis añadido). Tres de las versiones resaltan esta puntualidad de calendario y más de tres consideran que la mujer ahogó al niño cerca de donde se aparece. Podríamos ubicar este cronotopo en la esfera de un locus terribilis que encierra a La Llorona en un padecimiento circular y profundo. Dicen los campesinos boyacenses: "es que el cuerpo de la mujer ta en la cama, y el espíritu será el que lo lleva el diablo (no el buen-amigo, sino el diablo), pero no sé, porque el cuerpo tiene que andar ahí, esas viejas amanecen todas apaleadas. Yo no sé cómo será eso” (s. p. Énfasis añadido). “Entonces eso sí existe, la berrietas sí es cierto que existe, es el espíritu de la persona, pero dicen que se quedan dormidas y se les sale el espíritu” (Blanco, 2019, s. p.)..$^{5}$ Debido a la "transgresión" sociocultural, La Llorona es castigada en el mismo espacio y con la misma periodicidad. La mujer queda encerrada en el río y en la fecha de su "error", símbolos de dos elementos imprescindibles en las labores agrarias, agua y calendario, que aún nos hablan de una cosmovisión campesina, de una forma específica de vivir el año y el espacio que no admite rupturas bruscas.

La secuencia culpa-castigo esclarece el proceder del narrador al encontrarse con La Llorona. En todos los casos notamos que la reacción es impulsada por la misma leyenda (memoria colectiva) que es recordada en el momento del encuentro. Su reactivación en la percepción de la persona, inmediatamente rememora las palabras de otros que ya han tenido la misma experiencia. Aquí podemos dividir en dos las posibilidades de encuentro: la visión lejana de La Llorona en la que no hay necesidad de actuar, y el cruce cercano que sí exige reaccionar antes de que el miedo paralice el cuerpo. El imaginario colectivo aduce dos opciones que -en el estado de inacción física en que la visión deja a su observador- podrían ser consideradas patrones de hay curvas de río que son reconocidas solo porque ahí se ve a La Llorona. La fisonomía del niño descrita por Rafael Blanco, "arrugado y barbudo", también es un símbolo del paso del tiempo.

$5 \quad$ Estas reflexiones sobre el cuerpo y el espíritu del ser extrahumano tienden un puente con la cultura popular cervantina encarnada por la bruja Cañizares en el "Coloquio entre Cipión y Berganza”. 
acción fija: gritar groserías o rezar. Lo primero aleja a La Llorona y lo segundo la atrae porque aliviana su pena. En uno de los seis relatos aportados por Rafael Blanco (2019), queda registrada la cómica situación producida por la doble reacción: su cuñado reza mientras él maldice, con lo cual La Llorona se acerca y se aleja en un circo nocturno de varios minutos (dos cuadras). El primer factor a resaltar es el agua: "cuando íbamos llegando a ese puente sentimos un ruido y cuando volteamos a mirar vimos a la berrietas echando agua en el pozo, casi debajo del puente” (s. p.). Luego vienen las reacciones contrarias: "Misael se puso a rezar y no me dejaba caminar y se me colgó, y la berrietas por el otro lado y eso esas uñas y esas muelas tan horribles y desmechudada, y era a mandarnos las uñas. Yo lo que hice fue quitarme el cinturero y la agarré de la orilla y dígale groserías y el Misael rece” (s. p.). Lo que sucede a continuación es validado por la palabra popular: "Entonces, dicen así, que las aleja uno gritándoles groserías y si tiene uno un rejo amenazarlas a juete entonces, y dicen que al rezar ella se acerca más porque siente alivio” (s. p. Énfasis añadido). Misael, distanciado del imaginario compartido en el pueblo ("un hermano de mi señora que vive en Bogotá”), reaccionó espontáneamente, a diferencia de la comunidad culturalmente preparada para continuar el juicio contra la pecadora, tal como se aprecia en lo expuesto por Julia Sandoval (2019):

Y recordaba que decían que en ese momento uno no debía rezar porque al rezar uno alejaba al diablo que llevaba castigando al espíritu de la mujer que había matado al niño, que debía más bien maldecirla por haber cometido eso, porque era un crimen prácticamente matar al hijo. Rezar era ahuyentarle el castigo y no recé porque yo dije: que la siga castigando más bien por haber asesinado al hijo (s. p.).

Dentro de los marcos éticos de la comunidad, hombres y mujeres acometen contra la visión que les recuerda que no pueden errar (ni permitir errar) de forma tan censurada localmente. Si a Tántalo se le atribuyen los tres pecados mayores del pathos griego - el desafío a los dioses, la ofensa al huésped y el ataque a un niño-, La Llorona rompería tres instancias centrales elogiadas por el mundo judeocristiano: la vida, la infancia y la familia. Lejos de la castidad doméstica, La Llorona se vuelve una Medea que todos odian, sin dejar espacio para que la memoria recuerde los detalles de las razones que impulsaron el filicidio: el acto se ratifica en cada encuentro como punible. Pasa lo mismo con el personaje indoeuropeo más parecido en acción, reacción y castigo a la "berrietas": la Lamia. 
Aquel "chillido matroz"(Blanco, 2019, s. p.), que provoca desmayos, señala efectivamente el lugar de la oralidad. "La acción concentradora del oído (el campo del sonido, no se despliega frente a mí, sino que me envuelve) afecta la percepción que el hombre tiene del cosmos" (Ong, 1996, p. 77). A partir de lo escuchado, la visión de mundo del campo, el pasado que viaja para mantenerse en un oído hacia el futuro, "revive el tiempo original, traslada un conocimiento de carácter divino a la dimensión espacio-tierra" (Calderón, 2010, pp. 112-113). Es en la explicación colectiva de ese traslado - de generación en generación y de grito a oído- que se hace válido el juicio contra el pecado realizado.

De hecho, las groserías y golpes con que es atacada La Llorona por esa ética comunal están muy cerca del maltrato que reciben las mujeres violadas luego de realizar, también a escondidas, un aborto. En medio de su malestar físico, en vez de ser auxiliadas, las mujeres son torturadas para que confiesen por la fuerza lo que han hecho (Centro de Derechos Reproductivos, 2010, p. 20). Debido a este vínculo, consideramos que la leyenda de La Llorona también puede girar sobre sí misma para mostrar que la atacante, el "monstruo" al que todos le temen, también pudo haber sido atacada. En todo caso, la mujer que llora necesita una expiación más que superficial y no puede ser tocada por el elemento purificador, esencialmente intangible, como se observa en el relato de un informante: "es el espíritu de la persona, dicen que se quedan dormidas y se les sale el espíritu" (Blanco, 2019, s. p.). Es curioso que el castigador siempre sea el masculino diablo y que en un solo caso, el de Lisseth Sandoval (2019), La Llorona cargara a una bebé (s. p.) y no a un niño, como en todos los demás relatos orales recogidos. En todo caso, la purificación buscada es en esencia femenina, la mujer violentada se acerca a otra mujer para purgarse —uno de los ejemplos más maternales del agua es la Mama-Yaku andina, esencial en la cosmovisión yanakona-. El agua pues, no es una castigadora de La Llorona sino su compañera, la abuela que escucha su dolor.

Hemos hablado entonces de un cronotopo de pena cometida-castigo recibido, en el que el espacio es cotidiano, rural, y el tiempo termina siendo cíclico. Estos castigos casi siempre ocurren en los tiempos y espacios de la noche, por lo que en dos relatos que cuentan la aparición triple de La Llorona, el niño y el diablo sobresale la mención de la luz, como si fuera más profunda y dolorosa la visión del castigo (fuego) que la del pecado. Uno de los narradores cuenta que "al final ya no veía bultos ni nada, sino la sola llamarada en redondo. Cuando crucé llegué a la casa y a lo que vide la luz 
de la esperma me desmayé” (Mesa, 2019, s. p.). En la versión transcrita más arriba, el padre de Rafael lo salva del vértigo evitando la luz, porque ya conoce la leyenda y sabe que es mejor ocultar la verdad y no encender la vela.

\section{Duende de aire}

E1 segundo relato ha sido recogido de cuatro voces distintas en entrevistas separadas. Si bien hay pequeñas variantes, las versiones nunca se distancian de su tema central y mantienen un hilo común. La versión contada por Julia Sandoval (2019) nos deja ver dicha estructura. Elijámosla como eje central y de nuevo vayamos resaltando los rasgos de espacio y tiempo:

En el campo, aquí en la vereda de Cardonal (esto que estoy contando es de hace muchos años atrás cuando yo estaba una joven, una niña, prácticamente), una señora dizque salió a chiquerar, a apartar a los terneros, separarlos de las vacas para madrugar al otro día ir a ordeñar. Y llevaba a un nieto dizque muy bonito y mientras ella iba a recoger a los terneros el niño desapareció. Ella se fue a la casa, a buscarlo, a preguntar si el niño se había vuelto para la casa y no. Pasaba una quebrada por ahí, lo buscaron por toda esa quebrada, arriba-abajo, en todos los potreros y no lo encontraron: el niño desapareció. Ni lo encontraron en el río, ni lo encontraron en el potrero, el niño desapareció por obra mágica, pongámoslo así. Pasaron unos días y ya se fueron hacia arriba, a la montaña, un señor a buscar unas cabras, entonces ya fue y encontró el cuerpo del niño, entre unas matas de espino, ${ }^{6}$ contaba él, y que el niño estaba allá y que prácticamente había muerto de frío.

También decían que era que el niño era muy bonito y se lo había llevado el duende y lo había alcanzado a llevar para arriba, hacia la roca, y que lo había dejado allá entre unas matas de espino, que allá estaba el cuerpecito del niño. Que inclusive se hacía raro que junto al niño había unas galleticas, y comentaban en esa época que el duende cuando hacía fuertes vientos, y que en esa época no había tantas vitrinas como ahora, las panaderías colocaban sobre unas bandejas o en unas canastas lo que hacían: el pan, colaciones, galletas, todo eso. Y comentaban que el duende entraba y, como son espíritus que no se ven, se robaban las galletas o algo. $Y$ allá le encontraron sí dizque unas galletas junto al cadáver del niño. Que prácticamente el niño estaba así rasguñadito y murió de frio (s. p. Énfasis añadido). ${ }^{7}$

El regocijo en los detalles espaciales es evidente. "Los buenos narradores se ocupan de indicar los espacios geográficos claramente y suelen darle bastante lugar a este tipo de información" (Álvarez, 2012, p. 82). Otras versiones dan más detalles sobre el tiempo. Rafael Blanco (2019), por ejemplo, comienza su relato dando cuenta de su relación con el niño desaparecido: "En 1956, yo estaba estudiando en la escuela de Cardonal

Así como con las peñas, la relación con lanzar o dejar a las víctimas en espinos o en arbustos hirientes aparece en narraciones orales protagonizadas por el diablo o los demonios, recogidas en Ventaquemada, Villa de Leyva y Susacón.

$7 \quad$ El clima puede ser uno de los ejemplos más claros de que no tiene mucho sentido tratar por separado al tiempo y al espacio: ¿qué es morir de frío si no estar a la intemperie (el afuera de la indefensión) en una hora indebida (el amanecer, la noche)? 
y había un muchachito al que lo llevaba al colegio el hermano. El muchachito no me acuerdo cómo se llamaba, el hermano era Serafín Gómez y traía al chinito de unos cuatro añitos" (s. p.). En la versión de Etelvina Sandoval (2019) se ratifica esa época: "Cuando yo vivía onde mi comadre Lola, hace unos sesenta años, una señora se fue a ordeñar al lado del río y dejó al chinito ahí al pie de las vacas y llegó el duende y se lo alevantó, lo fue a escargar arriba al páramo" (s. p.).

Todas las versiones hacen evidentes los rasgos de un vínculo colectivo sólido que participa en la trama y en el registro oral de lo contado: "no lo topó, no lo topó, y llore la señora y por allá dio aviso a los vecinos y el niño se perdió y dijeron: eso fue el duende que se lo llevó, y busquen a ese niño por esas peñas, por allá lo toparon, eso lo mató el duende, lo toparon muerto, se lo cargó el duende" (Lagos, 2019, s. p. Énfasis añadido). $\mathrm{E} 1$ discurso tiende a ratificar un rumor que todos reconocen como verdadero conectándolo con la fe de los demás: "eso pasó porque el cabrero lo vio", "es cierto porque yo estudiaba con el hermano y el niño no volvió", "si don Rafa también se lo contó entonces no es mentira lo que le estoy diciendo".

Veamos la secuencia narrativa de esta leyenda. Hay tres escenas básicas: la circunstancia cotidiana del niño y de la tía en el potrero (solo aparece como abuela en una variante), el rapto y la muerte. Podríamos fragmentarlos en dos motivos que forman su propio cronotopo: el mundo del idilio y la pérdida-descubrimiento. Como se trata de un infante, la demarcación bajtiniana del idilio se reduce a los ámbitos de la familia (con su porción de amor) y del trabajo rural, en este caso no específicamente agrícola. Es la vida pastoril en su puro comienzo: cuando el niño aprende de los adultos su deber ser en el campo. El terruño estaría destinado dualmente a ser su cuna y su tumba, pero el relato es trágico porque se trunca la conexión entre nacimiento y vejez. El duende es cruel y odiado porque se lleva a los más indefensos. En algunas comunidades, su intención está conectada (en tono ejemplarizante) con la demora en el ingreso a lo religioso: el rapto del niño-no-bautizado (Terrón, 2007, p. 162). En ambos casos se rompe la vida feliz de espacio ameno y tiempo cíclico del microuniverso del idilio.

Es ahí donde aparece la ferocidad del rapto: el niño que estaba echando raíces es raptado por el duende aéreo. Es en la intersección enérgica entre espacio y tiempo, y en la voraz relación entre los elementos (en que se produjo la vida) donde la narración gana valor estético. El rapto ocurre por la tardanza de la mujer que no lleva consigo al niño, por la separación en una relación que se suponía centrada en proteger y acompañar al 
otro. Visto desde otra perspectiva, el rapto nos recuerda un detalle que Bajtín (1989) otorga a las novelas tardías de aventuras, en las que aparece la intervención del destino a través de las fuerzas irracionales de dioses, demonios, magos-hechiceros que, "en tanto que malvados, utilizan como instrumento la simultaneidad casual y la non simultaneidad casual, 'acechan', 'esperan', se arrojan 'de repente' y 'precisamente' en ese momento" (p. 247). Si bien los relatos recogidos no realizan esas conexiones sintácticas que obedecen más a la escritura, dejan implícita la callada cacería del expectante duende.

El rapto es visiblemente vertical. El duende secuestra al niño y asciende con él hacia un espacio que los demás desconocen: "lo alcanzó a llevar para arriba, hacia la roca” (Sandoval, J., 2019, s. p.), "se lo alevantó” (Sandoval, E., 2019, s. p.), "se lo cargó” (Lagos, 2019, s. p.), "hoy le llaman La Cruz del Niño, allá donde lo encontraron, eso ya es llegando a la punta del cerro" (Blanco, 2019, s. p.). Lo particular en este caso es la dirección del viaje, pues no se trata de una caída sino de un ascenso, comúnmente vinculado al mérito de la gloria. Esto coincide con la visión de tornado que ofrece el duende en Susacón. Siendo niño, Rafael Blanco (2019) era perseguido por el duende. En aquellas ocasiones, el viento acompañaba su visión del "payasito, morraquito con sombrero lleno de cintas, lleno de colores”, que le hacía señas: “cuando se me acercaba se aparecía un remolino, hacía remolino, taba a la pata mía, y yo me fui corriendo"(s. p.). Etelvina Sandoval (2019) afirma que una tía suya también fue raptada por el duende:

Una vez alevantó a mi tía Lucía y mi abuelita dizque la alcanzó de los pies, le echó las naguas en la cabeza a mi abuelita, pero ella favoreció su china, la agarró de los pies, así, si se demora más no la alcanza, se la lleva el berriondo duende (s. p.).

También estuvo entrometiéndose en la labor agraria de Saúl Lagos (2019), en su infancia:

Tábamos con mi papá Pedro en el patio de mi abuelita Tomasa, aporreando un poco de alverja, eso era a palo. Y vino un medio huracán, y cuando sentimos que bajaba por así zorcona, una vaina, un viento, y ese ruido y era aporreando un cuero, eso se sentía esa vaina. Y ahí mismo dijo mi papá: iel duende, el duende! (s. p.).

En los casos más famosos de ascensos - Ganimedes, Enoc, Elías, Yudhishthira,Jesús, o Apolonio de Tiana-, los elevados fueron elegidos por los dioses por haber tenido vidas ejemplares. La imagen es tan estática y lenta que los ascendidos y los testigos (si los hay) no reaccionan. Notémoslo en el relato de Julia Sandoval (2019), en el mismo pueblo donde (una vez más) parece haber ocurrido la escena de Remedios la Bella: 
Salí un día como a la una de la tarde de una casa a cruzar a donde una tía, cuando vi que salió una niña bonita, crespita, salía de la casa de la abuela de ella para abajo. Cuando de buenas a primeras fue que yo la vi que se fue elevando, elevando, elevando, pero yo no veía nada que la estuviera sosteniendo sino que la iba viendo a todo nivel, iba ella subiendo, subiendo ahí, cuando ya iba dando a terminar el tejado, el techo de la casa que es de don Rafaelito Blanco, salió una señora y se dio cuenta de que la niña iba así porque la niña ni lloraba ni decía nada, y comenzó la señora a decir: san Jerónimo, san Jerónimo, el duende se llevó a la niña y ella lo que decía era: san Jerónimo, san Jerónimo, san Jerónimo. La niña volvió y bajó a nivel y quedó paradita en el mismo punto del que fue levantada, pero la niña tranquila, ni lloró, estaba pasmada. Y decían que era el duende que se la quería llevar (s. p.).

Se desconoce la relación entre el santo y el duende. En el relato del payasito multicolor, la familia de Rafael Blanco (2019) lo salva usando un animal que vive entre saltos (obligándolo a quedarse en tierra) y un instrumento de viento: "me hacían llevar un gato de cabestro y tocar una flauta, porque el duende es músico y odia que lo arremeden" (s. p.). La rápida reacción de la madre, la invocación del santo y el uso de amuletos salvaron a los niños a los que el duende pretendía raptar.

Comparado con el fenotipo etéreo del duende observado en esta región de Boyacá, la descripción del duende jujeño de los relatos orales recogidos por Elena Bossi (2004) en la tradición argentina dibuja a un ser de tierra que lanza piedras, empuja víctimas a los precipicios y las minas, tiene una fuerza sobrenatural para atacar a más de un hombre, odia el excremento, vive entre viñas e higueras, duerme en hornos de barro y le gusta estar en los arenales (pp. 23-25). Este contraste en la conducta de la tierra y el aire nos permite evocar las ideas de Cohen y Duckert (2015) cuando afirman que "los elementos engendran una caída de la perspectiva, un cambio inestable entre los marcos familiares y domésticos, y las desorientaciones de un mundo salvaje que puede estar distante o estar dentro" (p. 19). La aparición, nunca esperada, de ese mundo salvaje implica la ruptura del idilio campesino que, según Bajtín, sujeta a las personas a un espacio específico. Esta situación drástica que separa al niño de su tierra y de su familia ejemplifica la observación de Colombres (1995), según la cual "nuestras leyendas [americanas] suelen ser trágicas, por el simple motivo de que algo debe morir para que algo nazca” (p. 20). ¿Pero qué nace? ¿La precaución colectiva, el miedo o la fama del raptor? Incluso la desaparición social del niño puede ser el surgimiento de un duende nuevo, un aprendiz de duende anteriormente raptado por otro, educado de otra forma en la cueva para perpetuar su falta de roce social: "el duende es un ser chiquito de unos cuarenta o cincuenta centímetros, un niño que ha muerto sin ser bautizado" (Bossi, 2004, p. 23. Énfasis añadido). En el paso de humano a duende, el niño 
deshabita las horas (largas) y los lugares (amplios) de su vida — hogareña, de primeros descubrimientos - para entrar en otras formas de realidad que le permiten aparecer solo en algunas fechas, parajes y circunstancias específicas. La atracción que provocó en el duende convierte al niño en receptáculo de una irrupción salvaje que lo empuja al limbo entre la vida y la muerte, lo angelical y lo profano, la ingenuidad de la infancia y la sabiduría de la vejez, hasta que finalmente se apropie de su nueva identidad.

Sigamos indagando en las circunstancias de la muerte del niño. Para ello agreguemos un final más detallado, el de Rafael Blanco (2019):

Entonces decían, quién sabe si será cierto, que el duende se lo había llevado, pero que el muchachito tenía una medalla y un Cristo, que se lo tenían colgado, y al tener todo eso colgado que el duende lo había abandonado y que el niño había muerto allá, o que el duende lo había matado o pues en quince, veinte días cंcómo iba a sobrevivir el chinito? (s. p.).

Sumemos la explicación de un quinto informante, Álvaro Mesa (2019):

El duende es un espíritu que vuela, según las características es un espíritu rubio, que se presenta como cualquier criatura, lo que pasa es que él es de ojos verdes y mono, el macho persigue a las hembras y la hembra persigue a los machos, a los niños que no hayan tenido contacto humano con los otros humanos, sin roce social con el humano. Y los llevan a los desiertos o a los cerros, y los mantienen con dulces, como no pueden comer sal los mantienen con solas cosas de dulce. Cuando se llevan a un criaturo de esos, lo mantienen allá y a veces hacen cruz, y como el humor del duende seca a la persona y la mata, o si el humano tiene alguna patente no lo pueden dentrar a las cuevas: una medalla bendita, un escapulario, algo así que esté bendito por un cura. Entonces los dejan por allá en el desierto, por ahí, o en barrancos donde no se pueden bajar y allá por allá mueren de frío (s. p.).

La medalla religiosa y la cueva hacen referencia a la figura del amuleto. En la tradición de los relatos orales su presencia es muy recurrente e importante. El escapulario que debió salvar al niño en realidad lo condenó, como si el duende ejerciera una resistencia contra la religión impuesta, como si intentara mantener un pasado que estaría en medio del tiempo primordial del mito (con otros dioses y seres) y nuestro tiempo humano.

La versión de Álvaro Mesa coincide con datos complementarios de Saúl Lagos y Rafael Blanco, según los cuales hay duende y duenda, deseosos de raptar niños bonitos del sexo opuesto, con muy poco roce social. A pesar del gusto que los infantes podrían despertar en los duendes, los relatos carecen de intenciones sexuales, como si solo hubiera una afectividad respetuosa hacia los secuestrados, tan vigilante y misteriosa como la adoración de los hombres hacia los dioses. 
En cualquier caso, si Bajtín (1989) recuerda a Hegel en cuanto a que la novela debe educar al hombre para la vida en la sociedad burguesa (p. 385), aquí cabe la extrapolación de que la leyenda - sobre todo cuando se desenvuelve en sus oriundos marcos orales - le permite desaprender para retornar al mundo idílico, y no le sea traumático encontrarse allí a otros seres. $\mathrm{O}$ también para que tenga una memoria comunal que le permita reaccionar con la ayuda de un saber colectivo.

A partir de este ejemplo, formulamos el cronotopo central del género de la leyenda como el tiempo de aparición de lo fantástico en un mundo familiar-cotidiano muy bien delimitado (Colombres, 1995, p. 20), en el espacio - en el campo, en la vereda Cardonal, en la cueva de la Cruz del Niño- y en el tiempo — hace sesenta años, después de 1956-. En términos de Bajtín, esta leyenda específica estaría conformada por una no-simultaneidad que protagoniza el primer momento de la secuencia narrativa: 1) el hecho central sucede justo cuando la tía no se encontraba en el mismo lugar que el niño — se pasa del con al sin, del cerca al lejos, del suelo al cielo-. En una segunda mitad narrativa, el niño entra en un tiempo y un espacio ajenos: 2) el rapto se hace hacia un lugar alto y escabroso, en un tiempo que nadie percibió; y 3) hay un transcurso de un par de semanas — vacías de información para el pueblo- en las que el niño es rechazado de aquel otro-lugar y muere. El idilio campesino se rompe por un ser de otro tiempo. El trabajo de la leyenda es el de preparar al ser humano para esos encuentros inesperados, como también vimos en el caso de La Llorona.

\section{Conclusiones}

Hemos examinado dos leyendas campesinas a partir del concepto de cronotopo formulado por Bajtín. En el primer caso, nos encontramos con una serie de relatos sobre $\mathrm{La}$ Llorona que comparte una línea narrativa y una explicación local que sigue la secuencia crimen cometido-castigo recibido, y construye su propio cronotopo: cuando uno de sus hijos nace, La Llorona lo aborta en un cuerpo de agua. Su penitencia consiste en reincidir periódicamente en dicho acto, cerca de las fechas y los lugares de los hechos. Se trata de un castigo cíclico en el que participan sobre todo tres entes: el niño abortado, el diablo que golpea con su fuete y La Llorona condenada a seguir sufriendo. $\mathrm{Al}$ interior del relato encontramos también el cronotopo del camino que describe un cruce atemorizante en el que la reacción de quien ve a La Llorona puede infringirle más dolor o proporcionarle alivio al espectro; en otros casos simplemente se la ve mientras pasa. 
En la segunda leyenda, un duende rapta a un niño cerca del páramo y lo lleva a un cerro en el que lo deja morir de frío. Nos encontramos con un tránsito violento desde el mundo del idilio campesino hacia una pérdida (rapto) que se da en una no simultaneidad: el breve momento en el que la tía se aleja permite el acecho del duende para llevarse al niño en un desplazamiento ascendente. Luego de un par de semanas y algunos kilómetros de búsqueda, se da la última etapa del cronotopo: el descubrimiento de que el niño ha muerto de frío a la intemperie porque un amuleto odiado por el duende le impide entrar a la cueva. Sumado a otros símbolos que aparecen en diversas variantes, este ascenso nos permite observar la sólida relación que guardan duende y aire en la tradición oral del pueblo visitado.

Esta búsqueda de las convergencias espacio-temporales nos lleva a indagar en la concepción de lo humano, en las visiones de mundo comunitarias que irrumpen en ambas leyendas: la vida campesina que castiga la infracción cometida, el no cumplimiento de roles (de madre o de tía) estipulados tácita o explícitamente. El aborto y el descuido son vistos como errores y se desaprueban con sanciones extremas de ruptura social. En el primer caso, el aborto es reprochado con violencia sin que nadie se tome el trabajo de indagar en sus posibles causas. En el segundo, la tía solo merece que el pueblo recuerde de ella lo que hizo mal, el instante en que dejó solo a un niño que aún no estaba listo para ser puesto a prueba por un encuentro fantástico. Los castigos implican también tiempo y espacio: el exilio (en pena circular a campo abierto) de la mujer en las quebradas más distantes, y el recuerdo constante de que el sobrino está enterrado bajo tierra o en una cueva (donde no se deja ver, como el viento) para ser adorado por un monstruo. La remembranza simbólica, que ocurre cada vez que las leyendas se cuentan, legitima el imaginario que la comunidad ha acordado sobre el deber ser de las madres y sobre cuándo debe salir el héroe al campo.

\section{Referencias bibliográficas}

Álvarez, G. (2012). Los relatos de tradición oral y la problemática de su descontextualización y re-significación [tesis de maestría no publicada]. Universidad Nacional de La Plata. Recuperado de: http://www. memoria.fahce.unlp. edu.ar/tesis/te.746/te.746.pdf [18-06-2020].

Arán, P. (2009). Las cronotopías literarias en la concepción bajtiniana. Su pertinencia en el planteo de una investigación sobre narrativa argentina contemporánea. Tópicos del Seminario 21, pp. 119-141. Recuperado de: http://www.scielo.org.mx/pdf/tods/n21/n21a5.pdf [18-06-2020]. 
Bajtín, M. (1989). Teoría y estética de la novela. Madrid: Taurus.

Blanco, R. (2019). Entrevista inédita. Susacón: sin publicar.

Bossi, E. (2004). Seres mágicos que habitan en la Argentina. Jujuy: Universidad Nacional de Jujuy.

Calderón, D. (2010). El encanto del Muan. Una aproximación al relato oral tradicional colombiano. En Trama y fondo. VI Congreso Internacional de Análisis Textual (pp. 109-118). Segovia: Universidad de Valladolid. Recuperado de: https://bit.ly/2R901VE [18-06-2020].

Castaño, A. (2014). Hidromitología y lecturas. Aplicaciones en educación, cultura y turismo [tesis de doctorado no publicada]. Universidad de Extremadura. Recuperado de: http://dehesa.unex.es/handle/10662/2046 [01-04-20].

Centro de Derechos Reproductivos (2010).Aborto y Derechos Humanos. Reproductive Rights. Recuperado de: https://bit.ly/3uCUmWL [22-06-2020].

Cohen, J.y Duckert, L. (2015). Eleven principles of elements. En Elemental Ecocriticism. Thinking with Earth, Air, Water, and Fire (pp. 1-26). Minnesota: University of Minnesota Press.

Colombres, A. (1995). Del mito al cuento. Oralidad. Rescate de la tradición oral y la memoria de América Latina y el Caribe 6 y 7, pp. 19-22.

Díaz González, L. (2007). Amantes que se desvanecen en el tiempo: la memoria etnográfica o la compleja significación de las leyendas. Revista de Antropología Social 17, pp. 141-164.

Illich, I. (2008). $\mathrm{H}_{2} \mathrm{O}$ y las aguas del olvido. En Obras reunidas II (pp. 394-518). México: Fondo de Cultura Económica.

Lagos, S. (2019). Entrevista inédita. Susacón: sin publicar.

Martos-Núñez, E. y Martos-García, A. (2015). Memorias e imaginarios del agua: nuevas corrientes y perspectivas. Agua y Territorio 5, pp. 121-131. DOI: https://doi.org/10.17561/at.v0i5.2539

Mesa, Á. (2019). Entrevista inédita. Susacón: sin publicar.

Ong, W. (1996). Oralidad y escritura. Tecnologías de la palabra. Bogotá: Fondo de Cultura Económica.

Sandoval, E. (2019). Entrevista inédita. Susacón: sin publicar.

Sandoval, J. (2019). Entrevista inédita. Susacón: sin publicar.

Sandoval, L. (2019). Entrevista inédita. Susacón: sin publicar.

Terrón, H. (2007). Lo que abuela nos contó: relatos orales de Jujuy. Jujuy: Intravenosa. 